\title{
TILLAGE IN RELATION TO RAINFALL INTENSITY AND INFILTRATION CAPACITY OF SOILS ${ }^{1}$ )
}

\author{
R. H. A. VAN DUIN \\ Laboratory of Physics and Meteorology, Agricultural Universtity, \\ Wageningen (Holland)
}

\begin{abstract}
SUMMARY
Starting from Darcy's law the rate of infiltration of water into homogeneous and layered soils has been given, considering downward movement of water as a capillary entry of water. If the moisture content of the soil is at field capacity, its rate of infiltration approaches to the rate of percolation, which is determined by the saturated permeability. The influence of an upper layer with relatively high permeability on the infiltration rate of the subsoil is small. Thus, loosening the surface layer of a soil increases its infiltration capacity until the upper layer is saturated, and further infiltration is limited by the percolation rate of the subsoil, which is considered to be at field capacity.

The average rainfall intensity decreases with increasing length of the period in consideration. Stagnation of water at the soil surface during periods with relatively high rainfall intensity may be prevented by cultivation. The highest surplus of rain occurs after a period when the tangent to the summation curve of precipitation with time is parallel to the percolation curve. A graph is given showing maximal rainfall surplus in dependence of the percolation rate of the soil. A decrease of the percolation rate with a factor 10 corresponds with an increase of this surplus with a factor 2 .

Cultivating a soil in view of its infiltration capacity appears not to be important if the percolation rate of the soil surpasses $1,5 \mathrm{~cm} / \mathrm{h}$, since the corresponding high rainfall intensities occur in summer only. During these months the soil is in general not bare, while potential evapotranspiration is high, as well as the infiltration rate and the storage capacity of the unsaturated soil. With low values of the percolation rate $\left(0.25 \geqslant K_{\mathrm{s}} \geqslant 0.025 \mathrm{~cm} / \mathrm{h}\right)$, and a potential storage capacity of the upper layer $X_{p}{ }^{\prime}=0.25$, a depth of the upper layer varying between 11 and $22 \mathrm{~cm}$ satisfies to store the maximal surplus of rain in Holland, even during extreme wet periods (rainfall frequency 1 to 10 years). The periods of rainfall corresponding to this maximal surplus of rainfall are 2 hours and 4 days for these limits of $K_{s}$. With periods of $18 \mathrm{~h}$ and one month the average rainfall intensities are the same as the percolation rates, viz. 0.25 resp. $0.025 \mathrm{~cm} / \mathrm{h}$. The total storage capacity of the subsoil is only limiting in the case of rather small depths or very low values of its average potential storage capacity.
\end{abstract}

\section{INTRODUGTION}

The removal of precipitation from the surface occurs by infiltration and evaporation, and also laterally in as far as the removal in a vertical direction is insufficient. By cultivation of the soil an upper layer is formed in which the potential storage capacity for water (i.e. the volume fraction of airfilled pores) is increased and in which infiltration of water takes place at a considerably higher rate than in the uncultivated soil. Thus, cultivation largely influences the uptake capacity of the soil for water, which is especially important during periods with high rainfall. Successively the following factors will now be discussed :

1 Infiltration capacity of the soil before and after cultivation.

2 Potential storage capacity of the cultivated layer and the subsoil in cases where a watertable or an impermeable layer restricts further infiltration.

1) Received for publication February 2, 1955. 
3 Rainfall intensity-frequency data, i.e. the frequency at which a certain rate of precipitation occurs and the duration of this rate, together with the evaporation if longer periods are considered.

It is the object of the present investigation to arrive at a quantitative relationship between the depth of cultivation and the amount of rainfall which can be absorbed by the soil. If the frequency distribution of intensity and duration of rainshowers is known, together with the infiltration capacity of the soil, the depth of cultivation for which runoff will occur, e.g. once in two years, or once in five years, can be calculated, and this factor may also be taken into account for arriving at a decision about the actual depth of cultivation in practice.

\section{INFILTRATION CAPACITY OF SOILS}

Infiltration of water into an unsaturated soil from a constant head of water at the surface may be considered as a capillary entry of water. From the saturated surface a wetting front penetrates into the soil. Water is supplied to this front from the saturated surface accross a transmission zone by capillary driving forces and by gravity.

The moisture content of the transmission zone has been found to be about $80 \%$ of pore space saturation. The average permeability throughout the entire zone, $K_{T}$,remains practically constant (BoDman and Colman, 1943). The total pressure potential $\psi$ arises from the capillary forces at the wet front, together with the depth of the wetfront, $z$; the pressure gradient is $(z+\psi) / z$. The penetration rate of the wetfront into a homogeneous soil, $V$, follows from Darcy's law:

$$
V=\frac{d z}{d t}=\frac{K_{T}}{\mathbf{X}_{p}} \frac{z+\psi}{z}
$$

$z=$ distance from the surface, $\mathrm{cm}$

$t=$ time , hours

$K_{T}=$ permeability of the transmission zone , $\mathrm{cm}$ hour-1

$X_{p}=$ potential storage capacity of the soil, approximately the difference between the moisture content of the transmission zone and the initial moisture content of the soil ; $X_{p}$ is expressed as a fraction of the total volume.

$\psi=$ capillary potential, depending on the curvature of the menisci near the wetfront; $\psi$ is assumed to have a constant value in the soil, and is expressed in $\mathrm{cm}$.

$i=$ total infiltration at time $t \quad, \mathrm{~cm}^{3} \mathrm{~cm}^{-2}$

Integrating with the initial condition $z=0$ at $t=0$ and assuming constant $\psi$, $K_{T}$ and $X_{p}$ gives :

$$
t=\frac{X_{p}}{K_{T}}\left(z-\psi \ln \frac{z+\psi}{\psi}\right)
$$

or, since $i=X_{p} z$ :

$$
t=\frac{1}{K_{T}}\left\{i-X_{p} \psi \ln \left(1+\frac{i}{X_{p} \psi}\right)\right\}
$$

If a zone with decreasing moisture content (wetting zone) is introduced between the transmission zone and the wet front, in agreement with the observations (Bopman and CoLMAN, 1943), the infiltration follows from eq. 1 in which the reciprocal of the permeability is substituted by: $\frac{d}{z} \frac{1}{K_{w}}+\frac{z-d}{z} \frac{1}{K_{T}}$ where $d$ indicates the depth of the wetting zone,

2) This formula has also been given by J. R. PHILIP, Soil Science, 77 (1954) 2 : 153-157. 
and $K_{w}$ its permeability. Integration with the initial condition $z=0$ at $t=0$ gives :

$$
t=\frac{X_{p}}{K_{T}}\left\{z-\psi \ln \frac{z+\psi}{\psi}+\left(\frac{K_{T}}{K_{w}}-1\right) d \ln \frac{z+\psi}{\psi}\right\}
$$

It is clear that the 3rd term depends on $z$, since $d$ has a definite value for $z>0$, while $d=0$ at $z=0$, and also depends on $K_{T}$ and $K_{w}$. The value of $K_{w}$ varies between 0 and $K_{T}$, thus the $3 \mathrm{rd}$ term is zero both for $K_{w}=K_{T}$, or $K_{T} / K_{w}=1$, and $K_{w}=0$, since $d=0$ in that case. This suggests that the 3rd term, which does not determine the flowing properties of the soil, but depends on these, is of secondary importance, and the infiltration may be described by eq. 2 .

The amount of water absorbed by a horizontal column of soil from a tension-free water surface has been found to be proportional to the square root of time, viz. $i=c \sqrt{t}$, where $c$ depends on the properties of the soil (e.g. Swartzendruber a.o., 1954). This follows directly from $v=d z / d t=K_{T} \psi / X_{p} z$ or $t=z^{2} X_{p} / 2 K_{T} \psi$ and $i=\sqrt{2} K_{T} X_{p} \psi t$ (cf eq. 1,2 and 3 ).

Kostrakov (1932) gives an empirical relationship for the first part of the infiltration versus time curve, viz $i=b t \beta$, where $\beta$ is about 0.5 , and the constant of proportionality $b$ is assumed to depend on the permeability of saturated soil, $K_{s}$. This exponential relation, which has often been verified, is in good agreement with eq. 2 , which for $0 \leqslant z \leqslant 0.5 \psi$ can be approximated by $z=a t^{0.55}$ (cf. fig. 2) or

$$
i=b t^{0.55}
$$

where $a$ and $b$ depend on $\psi, X_{p}$ and $K_{T}$, according to eq. 2 a.

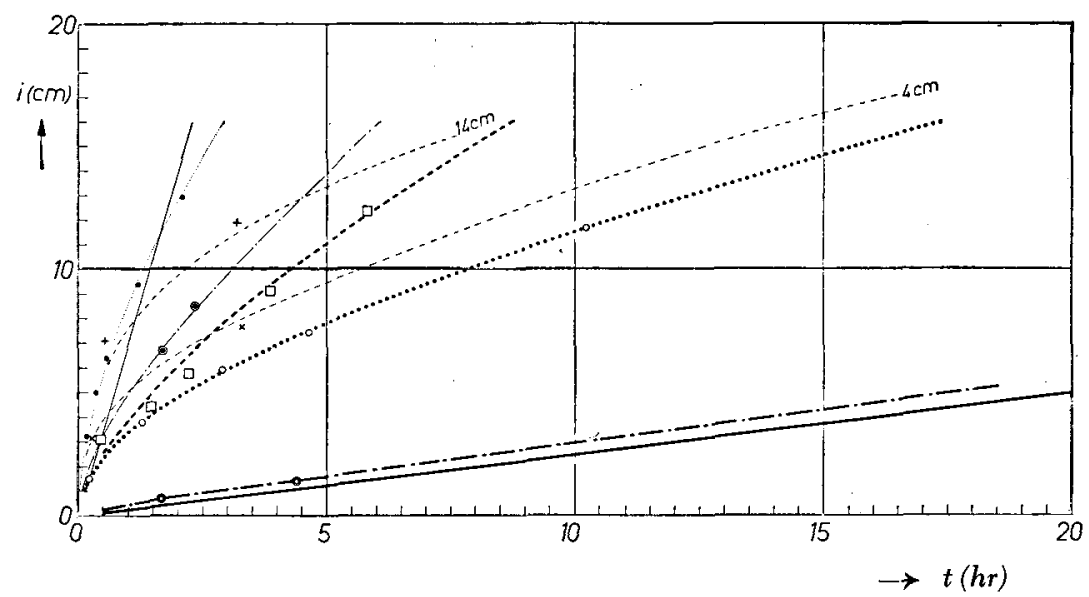

Fig. 1. Inflltration from a saturated surface, in Dependence of time. The data are taken from determinations by Bodman and Colman (1943) and Colman and Bodman (1944).

Sandy loam : Saturated : air dry: wet :

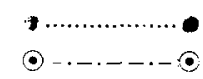

Silt loam :

Saturated : air dry : $\quad$ o............... wet : $\quad=-.-.-1-9$

$4 \mathrm{~cm}$ of sandy loam lying over silt loam :

$14 \mathrm{~cm}$ of sandy loam lying over silt loam :

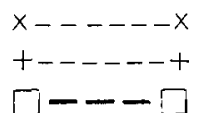


Fig. 1 represents some infiltration curves of dry and wet soils, which were taken from determinations by Bodman and Colman (1943) and Colman and BoDman (1944), while the corresponding properties are given in table 1 :

Table 1 .

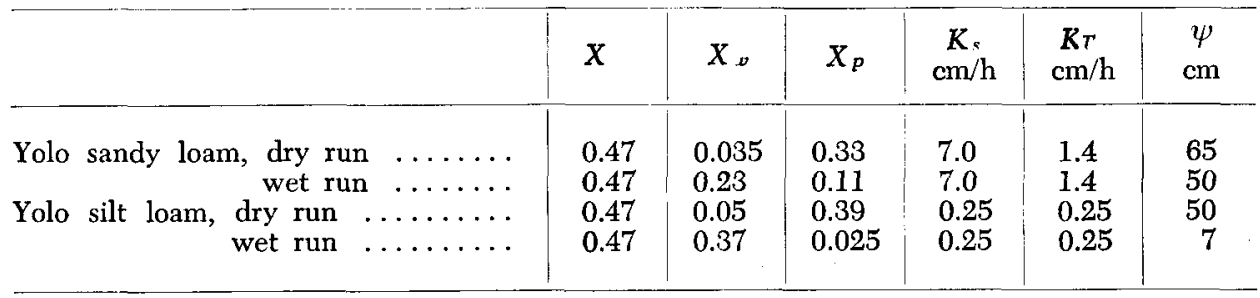

$X$ represents the volume fraction of solid material of the soil, which is constant with depth, and $X_{w}$ represents the volume fraction of water of the initial soil ; $\psi$ has been chosen in such a way that the calculated infiltration curves are in good agreement with the observations.

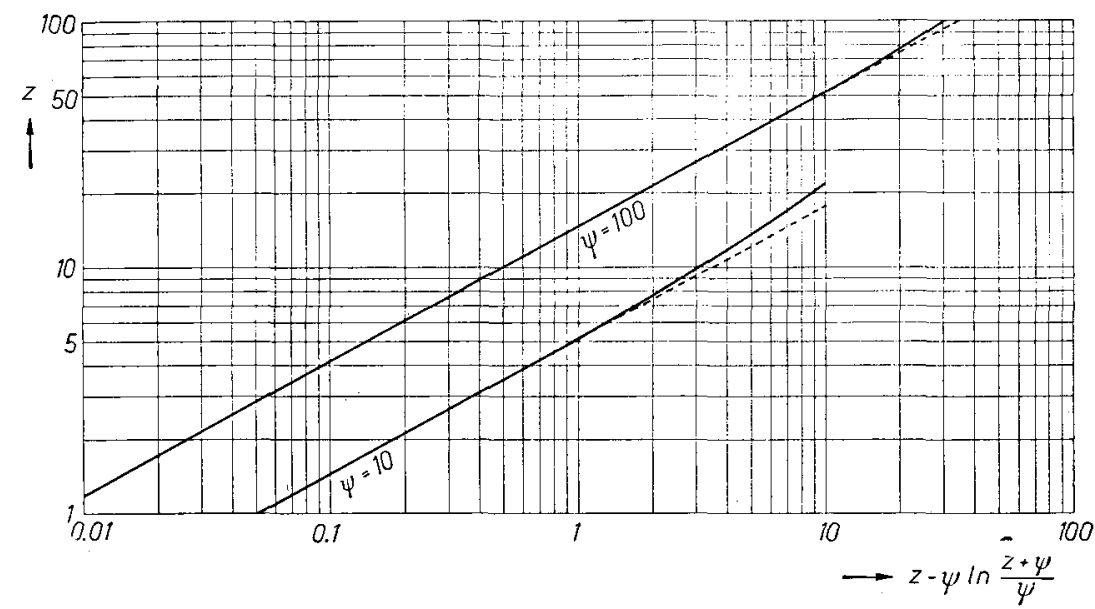

Fig. 2. Penetration depth of the wetting front, $z=i / X_{p}$, versus

$$
z-x \ln \{(z+x) / x\}=K_{t} t / X_{p} \quad \text { (cf. eq. } 2 \text { and 4). }
$$

In reality $X_{p}$ is not quite independent of $z$ and $t$, since the moisture content of the transmission zone slightly decreases with depth and increases with time, which also holds for $K_{T}$. In wet soils $X_{w}$ and $\psi$ are not wholly independent of $z$, since the moisture content of a drained soil increases with depth.

The sandy loam has a higher infiltration capacity than the silt loam (fig. 1), because of the higher permeability, which depends on the content of non-capillary pores. Since in the range of high moisture contents the permeability of fine textured soils decreases less rapidly with decreasing moisture content than does that of soils of coarser textures, there is a much closer agreement between $K_{s}$ and $K_{T}$ for the silt loam than for the sandy loam. The rate of penetration of the wet front is higher in a wet soil thans in a dry soil, the infiltration capacity, however, decreases with increasing moisture content. The latter phenomenon has often been observed (NEAL (1937), Horton (1933)), apart from several soils in 
a very dry condition, which show a remarkable resistance against wetting, since the angle of contact of the menisci at the wet front approaches $90^{\circ}$. The infiltration capacity of the fine textured soil with its moisture content at field capacity is not much higher than the infiltration capacity of the saturated soil ( $\psi=0$ ), which is given by $i=K_{s} t$. The infiltration capacity of the coarse textured sandy loam is even higher when this soil is saturated than if its initial moisture content is at field capacity.

When the soil consists of an upper layer with depth $d^{\prime}$, and a lower layer with different properties, extending to infinity, the infiltration into the upper layer $\left(z \leqslant d^{\prime}\right)$ is given by eq. $2 \mathrm{a}$, while the infiltration into the lower layer follows from eq. 1 , where the reciprocal of the unsaturated permeability of the trans-

mission zone is substituted by $\frac{d^{\prime}}{z} \frac{1}{K^{\prime} T}+\frac{z-d^{\prime}}{z} \frac{1}{K_{T}}$ and the dashed symbols refer to the properties of the upper layer. Integration with the initial condition $z=d^{\prime}$ at $t=0$ gives :

$$
t=\frac{X_{p}}{K_{T}}\left\{\left(z-d^{\prime}\right)-\psi \ln \frac{z+\psi}{d^{\prime}+\psi}-d^{\prime}\left(1-\frac{K_{T}}{K_{T}^{\prime}}\right) \ln \frac{z+\psi}{d^{\prime}+\psi}\right\}
$$

while

$$
i=d^{\prime} X_{P}^{\prime}+\left(z-d^{\prime}\right) X_{P}
$$

If the more permeable soil occupies the upper position, its moisture content is consistently higher than it is in a uniform column of the same texture, and positive values of pressure potential are found in this layer; the moisture distribution in the underlying soil corresponds to that in a uniform column of this texture, as was found by Colman and Bodman (1944). Some of their measurements with varying depths of the upper layer are represented in fig. 1. The properties of the upper and lower layers, which were used to calculate the infiltration capacities, are derived from their data (table 2).

Table 2.

\begin{tabular}{l|c|c|c|c|c|c|c|c|c}
\hline & $X_{s} \cdot$ & $X_{w} \cdot$ & $X_{p} \cdot$ & $\begin{array}{c}K_{T}^{\prime} \\
\mathrm{cm} / \mathrm{h}\end{array}$ & $X_{s}$ & $X_{w}$ & $X_{p}$ & $\begin{array}{c}K_{T} \\
\mathrm{~cm} / \mathrm{h}\end{array}$ & $\begin{array}{c}\psi \\
\mathrm{cm}\end{array}$ \\
\hline $\begin{array}{l}\text { Sandy loam lying over } \\
\text { silt loam ............. }\end{array}$ & 0.47 & 0.035 & 0.46 & 7.0 & 0.47 & 0.05 & 0.38 & 0.25 & 50 \\
$\begin{array}{l}\text { Silt loam lying over } \\
\text { sandy loam .............. }\end{array}$ & 0.47 & 0.05 & 0.43 & 0.25 & 0.47 & 0.035 & 0.28 & 0.60 & 65 \\
\hline
\end{tabular}

It appears that if the coarse-textured soil is lying over the fine-textured soil, water penetration into the soil beneath will proceed at about the same rate as if the soil surface were at the textural contact plane, because of the relatively high permeability of the upper layer. Thus, the total infiltration can be found from the value given by eq. $2 \mathrm{a}$, to which the storage capacity of the upper layer, $X_{p}{ }^{\prime} d^{\prime}$, must be added. Where the less permeable silt loam overlies the sandy loam, moisture contents in the sandy loam are consistently less than moisture contents at corresponding depths in uniform columns of the same texture, viz. 0,315 and 0,365 respectively. For this reason the permeability of the lower layer, $K_{T}$, will decrease with increasing depth of the upper layer. With the present example $\left(d^{\prime}=4 \mathrm{~cm}\right), K_{T}$ has been chosen to be $0,60 \mathrm{~cm} / \mathrm{h}$. 


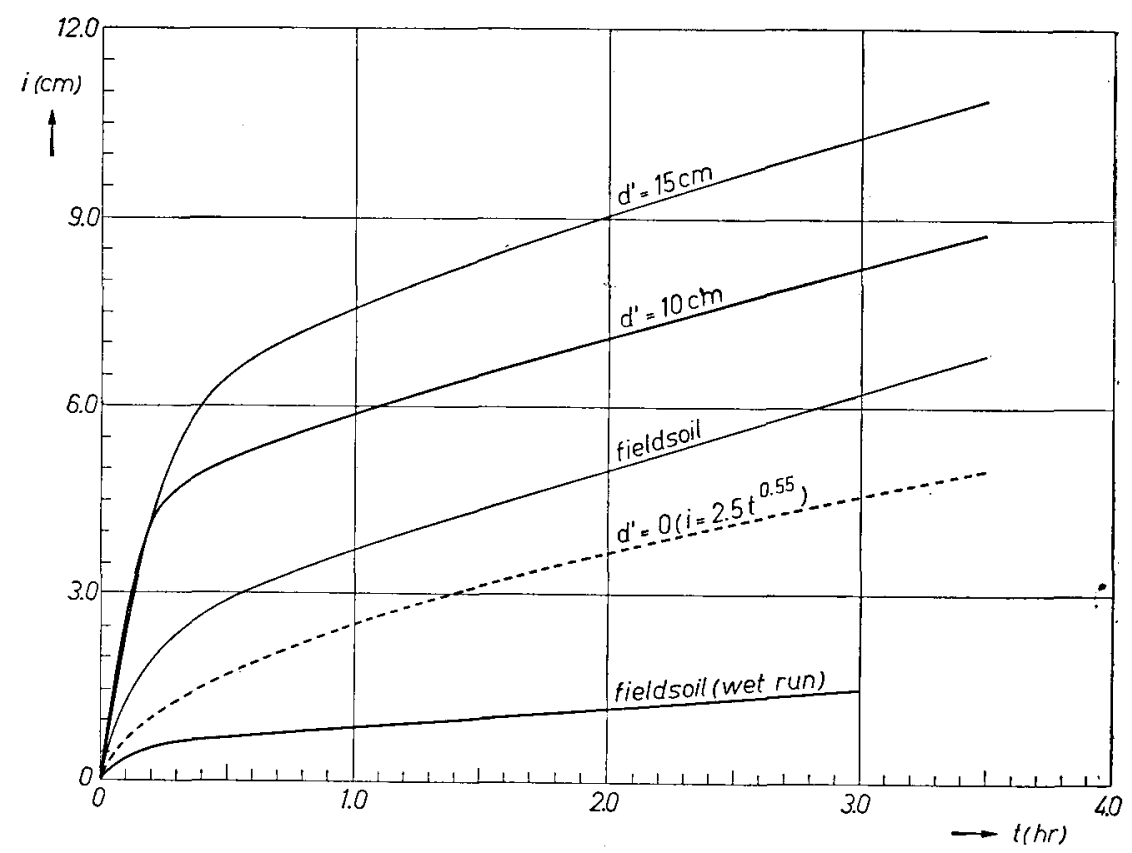

Fig. 3. INFILthation CAPacity of a SOIL With SEveral DEPTHS OF THE UPPER LaYer, $d^{\prime}$. The fulldrawn lines are taken from Musgrave and Free (1936).

Fig. 3 represents the results of some infiltration tests by Musgrave and FreE (1936), with several depths of a cultivated upper layer. It follows from their data that the potential storage capacity of the cultivated layer, $X_{p}$ ', is about 0.40 . If $d^{\prime}=0$ the infiltration rate may be represented by eq. 4 . Assuming $b=2.5$ this infiltration curve is nearly parallel to the experimental curves, but does not coincide with the fieldsoil curve, which indicates that the fieldsoil is not quite homogeneous. The total infiltration with different values of $d^{\prime}$ is fairly well represented by $X_{p}^{\prime} d^{\prime}+2,5 t^{0.55}$, as far as $z>d^{\prime}$. At the end of the infiltration tests, the amounts of infiltrated water are $5.0,6.8,8.8$, and $10.9 \mathrm{~cm}$, with $d^{\prime}=0$, fieldsoil, $d^{\prime}=10$ and $d^{\prime}=15 \mathrm{~cm}$ respectively, corresponding to a storage capacity of the upper layer of $0,1.8,3.8$ and $4.9 \mathrm{~cm}$.

In view of the results mentioned above, the following approximations seem admissible in the case before us :

1 The influence of cultivation on the infiltration capacity is determined by the potential storage capacity and depth of the upper layer.

2 The infiltration capacity of a fine textured subsoil may be represented by $i=K_{s} t$ as far as its moisture content is at field capacity (see fig. 1).

If cultivation results in a surface layer with less stability than the original soil, the infiltration rate and storage capacity of the upper layer may decrease below the corresponding values of the original surface layer. However, a change of structure stability will not be considered here and thus the properties of the upper layer are assumed to be independent of the depth of cultivation. 
Smith and Browing (1946) qualify the percolation rate of subsoils, $K_{s}$, as follows (table 3$)$ :

Table 3. Standards of subsoil permeability.

\begin{tabular}{|c|c|c|}
\hline $\begin{array}{c}\text { Permeability, } \\
K_{s}\end{array}$ & Description & \\
\hline $\begin{array}{c}>25 \mathrm{~cm} / \mathrm{h} \\
2.5-25 \\
0.25-2.5 \\
0.025-0.25 \\
0.0025-0.025 \\
<0.0025\end{array}$ & $\begin{array}{l}\text { very rapid } \\
\text { rapid } \\
\text { moderate } \\
\text { slow } \\
\text { very slow } \\
\text { extremely slow }\end{array}$ & $\begin{array}{l}\text { Coarse textured soils, having rather low water holding } \\
\text { capacities. } \\
\text { Soils with excellent water holding relations and per- } \\
\text { meability. } \\
\text { In the lower range of values aeration conditions may } \\
\text { be slightly limiting for sensitive crops. } \\
\text { Permeability too slow for favourable air-water rela- } \\
\text { tions and deep root development. } \\
\text { Poorly aerated soils. } \\
\text { Satisfactory as earth fill material. }\end{array}$ \\
\hline
\end{tabular}

ThE POTENTIAL STORAGE CAPAGITY OF THE SOIL

The potential storage capacity of a soil, which is connected to the volume fraction of non capillary pores, is highly influenced by tillage. Table 4 represents some results of an experiment by LiMENov (KLAUSE, 1931). The soil was plowed on May 30, July 3, and Aug. 7; the determinations, which are mean values of the results with different plows, were made in the cultivated layer.

Table 4.

\begin{tabular}{l|c|c|c|c}
\hline & $\begin{array}{c}\text { Before } \\
\text { May 30 }\end{array}$ & $\begin{array}{c}\text { May 30- } \\
\text { July 3 }\end{array}$ & $\begin{array}{c}\text { July 3- } \\
\text { Aug. 7 }\end{array}$ & $\begin{array}{c}\text { After } \\
\text { Aug. 7 }\end{array}$ \\
\hline Volume fraction of solid material, $X_{s}$ & 0.503 & 0.412 & 0.363 & 0.359 \\
Volume fraction of capillary pores . & 0.371 & 0.323 & 0.280 & 0.310 \\
Volume fraction of noncapillary pores & 0.126 & 0.265 & 0.357 & 0.331 \\
\hline
\end{tabular}

Cultivation almost redoubled the potential storage capacity of this soil, while the volume fraction of capillary pores, which indicates the moisture content at field capacity, was roughly proportional to the volume fraction of solid material.

To estimate the optimal depth of cultivation, the decrease of porosity with time must be taken into account. Moreover, it is questionable in how far full saturation of the upper layer damages the structure of this layer, and in how far it may be unfavourable to crop growth.

Sometimes the entrance of a waterfront into the subsoil is restricted to a limited depth by an impermeable layer or a watertable. The infiltration capacity of the subsoil is then given by the depth of this level, $d$, and the potential storage capacity of the subsoil, $X_{p}$, as far as no horizontal drainage of the soil occurs. Since the storage capacity also depends on the initial moisture content, it will increase during periods of dry weather, and, in general, will be highest at the end of the growing period.

\section{RAINFALL INTENSITY-FREQUENCY}

Fig. 4 represents the quantities of rainfall that can be expected to occur in 188 


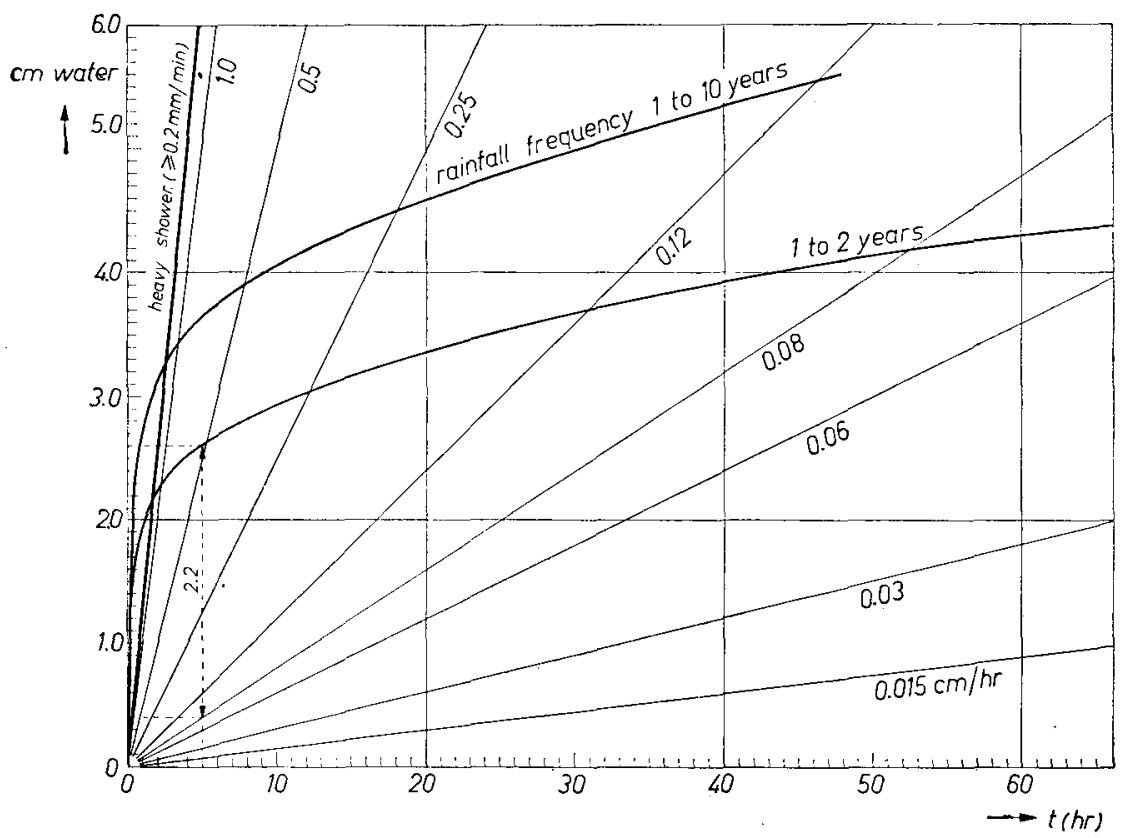

Fig. 4. Rainfall intensities with fRequencies of 1 to 2 years and 1 to 10 years, and INFILTRATION CAPACITIES OF HOMOgENEOUS, SATURATED SOILS. ThE HIGHEST SURPLUS OF RAIN OCCURS AFTER A PERIOD WHERE THE TANGENT TO A RAINFALL FREQUENCY GURVE IS PARALLEL TO THE INFILTRATION CURVE IN QUESTION.

Holland during a certain period at least 25 times and 5 times respectively in 50 years. (BRAAK, 1950). It appears e.g. that te rainfall during 24 hours will be $3.45 \mathrm{~cm}$ with a frequency of occurrence of 25 times in 50 years ( 1 to 2 years). For a two-day period ( 48 hours) this total quantity will be $4.15 \mathrm{~cm}$. Of course, the distribution of rain during such a period is not given by fig. 4 ; the rainfall during the second day even may be higher than during the first day.

The number of showers is greater in autumn, but the heavy showers (mean intensity $\geqslant 0.2 \mathrm{~mm} / \mathrm{min}$, or $\geqslant 1.2 \mathrm{~cm} / \mathrm{h}$ ) are of short duration, and for the greater part occur in summer (LEverT, 1951). From October to March the showers are of long duration and small intensity, and the evaporation is small, whereas the infiltration rate of the subsoil approaches its percolation rate and the potential storage capacity has its minimum value. Although fig. 4 only refers to quantities of rainfall during a certain lapse of time, and not to showers (i.e. periods of continuous rainfall), it is clear that the first parts of the curves of rainfall versus time refer to heavy showers, and these rainfall intensities are thus only to be expected in summer.

\section{RAINFALL SURPLUS}

Fig. 4 also represents the percolation rates of homogeneous soils, thus $i=K_{s} t$. The surplus of water for the period under consideration is given by the distance between such a percolation line and a rainfall intensity-frequency curve. The maximum value of this distance denotes the period with the highest surplus of rain, assuming that for each moment during this period $r \geqslant i$, where $r$ represents the total rainfall at time $t$. This surplus is e.g. $2.2 \mathrm{~cm}$ with a 


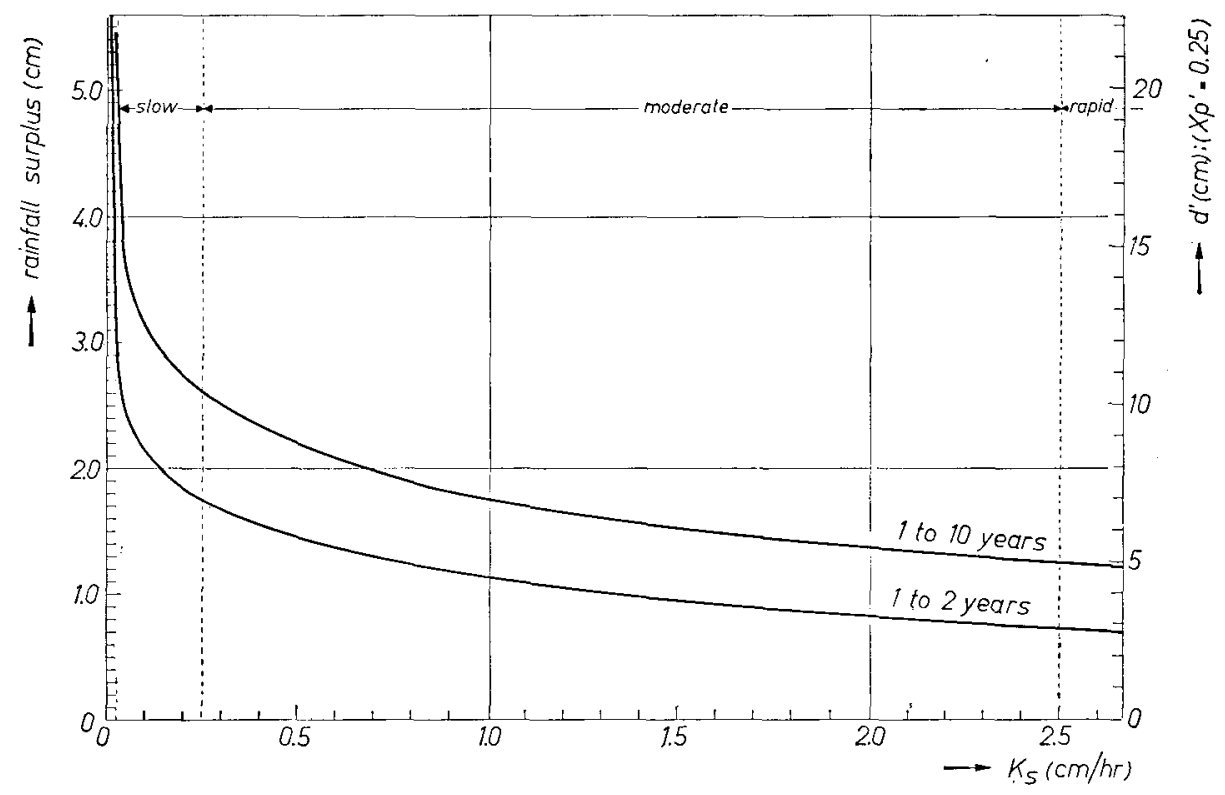

Fig. 5. Maximal Rainfall surplus in Dependence of the Rate of percolation of the SUbSOIL. The CORRESPONDING DEPTH OF THE UPPER LAYER WITH a POTENTIAL Storage CAPACITY $X_{p}^{\prime}=0.25$ IS GIVEN ON THE RIGHT HAND AXIS.

rainfall intensity-frequency of 1 to 2 years and a rate of percolation of $0.08 \mathrm{~cm} / \mathrm{hr}$, corresponding with a total rainfall of $2.6 \mathrm{~cm}$ in $5 \mathrm{~h}$.

Fig. 5 represents the maximal rainfall surplus in dependence of the rate of percolation of the subsoil, and neglecting the evaporation. A decrease of the rate of percolation with a factor 10 corresponds to an increase of the maximal rainfall surplus with a factor 2. These maximal values of rainfall surplus have relation to rather short periods of rainfall, as far as $K_{s}>0.25 \mathrm{~cm} / \mathrm{h}$ (cf table 5 and the "heavy shower curve" on fig. 4), which are only to be expected in summer. The periods with some surplus of rain are much longer than the periods of maximal surplus, as follows from fig. 4 and the last column of table 5 , where the periods with an average rainfall intensity equal to $K_{\mathrm{s}}$ are given.

The depths of the upper layer with a potential storage capacity $X_{p}{ }^{\prime}=0,25$ are given on the right hand axis of fig. 5. With low values of the rate of percolation $\left(0,25 \geqslant K_{s} \geqslant 0.025 \mathrm{~cm} / \mathrm{h}\right)$ a depth of the upper layer varying between 11 and $22 \mathrm{~cm}$ satisfies to prevent a surplus of rain, even during extremely wet periods; the duration of the corresponding periods with maximal surplus increases from $2 \mathrm{~h}$ to 4 days, whereas the periods with an average intensity $K_{s}$ are $18 \mathrm{hrs}$ and one month respectively.

The optimal depth of the upper layer also depends on the influence of a high water content of the surface layer on the stability of its structure and on crop growth. The depth of the upper layer as indicated in fig. 5 refers only to the storage capacity of water so as to prevent the occurrence of a surplus at the surface. It does not take into account the influence of a high water content of the upper layer on the aeration and the collapse of the structure.

The total storage capacity of the subsoil is given by $X_{p} d$, if the infiltration is 
Table 5.

\begin{tabular}{|c|c|c|c|c|c|c|}
\hline \multirow{2}{*}{$\begin{array}{c}\text { Rate of } \\
\text { percolation } \\
\mathrm{cm} / \mathrm{hr}\left(K_{V}\right)\end{array}$} & \multicolumn{2}{|c|}{ Maximal surplus of rain } & \multicolumn{2}{|c|}{$\begin{array}{l}\text { Duration of a period } \\
\text { with maximal surplus }\end{array}$} & \multicolumn{2}{|c|}{$\begin{array}{l}\text { Duration of a period with } \\
\text { an average intensity } K_{s}\end{array}$} \\
\hline & $1 \times$ in 2 yrs & $1 x$ in 10 yrs & $1 \times$ in $2 \mathrm{yrs}$ & $1 \times$ in $10 \mathrm{yrs}$ & $1 \times$ in $2 y r s$ & $1 \times$ in $10 \mathrm{yrs}$ \\
\hline 2.5 & $0.74 \mathrm{~cm}$ & $1.26 \mathrm{~cm}$ & $12 \mathrm{~min}$. & $15 \mathrm{~min}$. & 42 & $65 \mathrm{~min}$. \\
\hline 0.80 & 1.22 & 1.88, & & 45, & 3 & 4.5 hours \\
\hline 0.25 & $1.74 "$ & $2.66 ”$ & 1.5 hour & 2 hours & 12 & $18 \quad$, \\
\hline 0.08 & $2.20 \%$ & 3.28 & 5 hours & 6.5, & 52 & $84 \quad "$ \\
\hline 0.025 & $2.92 "$ & $4.68 ”$ & 2 days & 4 days & 17 & 31 days \\
\hline
\end{tabular}

restricted to a depth $d \mathrm{~cm}$ below the upper layer. Thus after $t=X_{p} d / K_{s}$ hours further infiltration is limited by the horizontal drainage capacity of the soil, this quantity being about $0.04 \mathrm{~cm} / \mathrm{h}$ if the soil is artificially drained and the groundwaterlevel is $30 \mathrm{~cm}$ below the surface (cf. VAN DER Molen, 1953). Since both $X_{n}$ and $K_{s}$ increase with increasing porosity, the lapse of time $t=X_{b} d / K_{s}$ depends for the greater part on the depth of the subsoil. With the groundwaterlevel at a depth of $80 \mathrm{~cm}$ below the upper layer at the beginning of the infiltration into the subsoil, and an average value of $X_{p}=0.06$, the total storage of the subsoil is $4,8 \mathrm{~cm}$, and the corresponding time lapse 1 day, if $K_{s}=0,20 \mathrm{~cm} / \mathrm{h}$. Such a quantity of rain during 1 day can be expected 5 times in 50 years, whereas $5.6 \mathrm{~cm}$ of rain during two days can be expected, with the same rainfall frequency. The discharge of this surplus of rain by artificial drainage takes $\frac{5.6-4.8}{0.04}=20 \mathrm{~h}$. This rough calculation indicates that only with rather small depths of the groundwater level, or if horizontal drainage fails, the total storage capacity of the subsoil may be insufficient.

\section{LITERATURE}

Bodman, G. B. and E. A. Colman : Moisture and energy conditions during downward entry of water into soils. Soil Sci. Soc. Amer. Proc. 8 (1943) 116-122.

BraAk, C. : Het klimaat van Nederland. Servire, Den Haag (1950) p. 31 and 73.

Colman, E. A. and G. B. Bodman: Moisture and energy conditions during downward entry of water into moist and layered soils. Soil Sci. Soc. Amer. Proc. 9 (1944) 3-11.

Horton, R. E. : The role of infiltration in the hydrolic cycle. Trans. 14th Ann. Meeting Am. Geol. Union (1933) 446-460.

KLAuse, M. : Russische Forschungen auf dem Gebiete der Bodenstruktur. Landw. Jahrb. 73 (1931) 603-690.

Kostiakov, A. N.: On the dynamics of the coefficient of water percolation in soils, and of the necessity of studying it from a dynamic point of view for purposes of amelioration. Trans. 6th Comm. Intern. Soc. Soil Sci. (1932) 17-21.

Levert, C. : Frequenties van regens, zware en zeer zware regens te De Bilt. Landbouwk. Tijdschr. 63 (1951) 641-704.

Molen, W. H. vaN DER: Bepalingen van de drainage afstanden door een morphologische beoordeling van het bodemprofiel. Landbouwk. Tijdschr. 65 (1953) 105-114.

NeAL, J. H.: The effect of the degree of slope and rainfall characteristics on runoff and soil erosion. Missouri Agr. Exp. Sta. Research Bull. 280 (1937).

Musgrave, G. W. and G. R. Free : Some factors which modify the rate and total amount of infiltration of field soils. J. Am. Soc. Agron. 28 (1936) 727-739.

SMrth, R. M. and D. R. Browning: Some suggested laboratory standards of subsoil permeability. Soil Sci. Soc. Amer. Proc. 11 (1946) 21-26.

Swartzendruber, D., M. F. DE Boodt and D. Kirkham: Capillary intake rate of water and soil structure. Soil Sci. Soc. Amer. Proc. 18 (1954) 1-7. 